\title{
DEZ ANOS NAS ONDAS DO RÁDIO
}

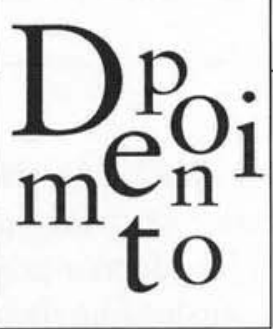

\section{De estagiário a produtor de rádio, sem abrir mão da qualidade da programação}

Minha história como radialista começou em 1989, quando ainda fazia meu curso de graduação na Faculdade de Comunicação da Fundação Armando Álvares Penteado, FAAP.

Eu estava com 22 anos e Teresinha Campos, na época companheira de estudos, estava procurando alguém para substituí-la em um estágio na Fundação Padre Anchieta - Centro Paulista de Rádio e TV Educativa. Teresinha havia ascendido um degrau na escala dos estagiários, estava saindo do atendimento ao ouvinte das rádios, localizado no térreo, para estagiar na produção da Rádio Cultura AM, no primeiro andar. Teresinha fez a indicação, Neuza Hernandes entrevistou e eu passei a ser o mais novo estagiário das Rádios Cultura AM e FM. Porém, antes de falar sobre os projetos que venho desenvolvendo ao longo desses dez anos (incluídos os de estágio), um pouco de história.

O início das transmissões da Rádio Cultura AM data de 1936, quando ela ainda era propriedade da família Fontoura e, nessa época, seu objetivo já era divulgar as atividades artístico-culturais de São Paulo. Em 1959 foi adquirida pelo grupo Diários Associados, que a transferiu, no final dos anos 60, juntamente com a TV Cultura, para o controle da Fundação Padre Anchieta.

Em 1970 desenvolveu seu primeiro projeto educacional: o curso supletivo de primeiro grau, que integrava as emissões do Projeto Minerva, para todo o país. Durante anos foram criados e veiculados diversos programas voltados ao ensino básico.

Na década de 80 a Rádio Cultura $\mathrm{AM}$ dedicou-se à produção de programas educativos mais ágeis, que misturavam informação e entretenimento, por exemplo o programa Matéria-prima, que, anos depois, foi reestruturado e adaptado para a televisão, obtendo enorme sucesso de público e crítica.

Já a Rádio Cultura FM começou a operar em 1971, transmitindo a mesma programação da Rádio Cultura AM e, em 1977, passou a transmitir uma programação própria, dedicada ao repertório erudito (o grifo é meu).

O AUTOR João Antônio Batista Radialista na Rádio Cultura, São Paulo. 
Segundo o dicionário Michaellis, erudito significa: "que tem instrução vasta e variada, que revela muito saber". Na minha opinião o termo erudito denota preconceito em relação a quem aprecia e a quem faz música que não se enquadre nessa classificação. Será que um compositor popular não é dotado de instrução vasta e variada? E quem ouve música popular? Talvez o termo música de concerto fosse mais apropriado, porém não é amplamente aceito por quem aprecia esse gênero musical.

Bem, quando cheguei à Rádio Cultura em 1989, tanto a rádio AM quanto a FM estavam passando por uma reestruturação. Thaís de Almeida Dias e Maria Luiza Kfouri assumiam a direção artística das Rádios Cultura FM e AM, respectivamente. Durante alguns meses trabalhei no atendimento telefônico ao ouvinte, até que consegui subir um degrau na escala dos estagiários e fui para o primeiro andar trabalhar com José Roberto Prazeres, diretor de programas da Rádio Cultura FM.

Meu primeiro trabalho foi produzir, sob sua supervisão, a série Festival de música do Norte da Índia. Ainda com José Roberto Prazeres produzi programas para a série Moderna - A música do século XX, Música vocal, Filarmonia e o especial Cabaré Kurt Weill, entre outros. Foi nessa época que tive a oportunidade de trabalhar com a musicista e radialista Regina Porto, que, além de produtora da Rádio Cultura FM, dirigia um ousado projeto nas Oficinas Oswald de Andrade.

\section{BISCOITOS FINOS}

Atenta ao que de mais significativo se produzia, e ainda se produz, nas rádios de todo o mundo, Regina Porto desenvolveu um projeto para o centenário do nascimento de Oswald de Andrade, homenagem que foi realizada pela Secretaria de Estado da Cultura de São Paulo com a colaboração da Fundação Padre Anchieta. Após quinhentas horas de trabalho - divididas entre ateliês de rádio, coordenado por Regina Porto; Literatura, coordenado por Fernanda Pompeu; Acústica, coordenado por José Augusto Manis; palestras e gravações -, foram produzidas quatro peças radiofônicas, ou Hörspiel.

Segundo Regina Porto, "o Hörspiel (ou peça radiofônica) é um gênero de grande tradição na Alemanha, onde nasceu nos anos 20, com adaptações de obras do drama e da literatura. Com o tempo adquiriu autonomia criativa a ponto de, em muitos casos, suprimir a narrativa linear e criar uma dramaturgia sonora própria. Seu valor decisivo continua sendo a palavra, à qual subordinam-se o ruído e a música (...). Com o Neue Hörspiel, que surge a partir da década de 60, o gênero atinge seu radicalismo acústico máximo. Influenciado pela poesia ex- 
perimental e não-semântica, eliminando qualquer hierarquia de valor entre os componentes e incidentes sonoros"1.

No mês de setembro de 1990, mergulhados no espírito oswaldiano, apresentamos, no extinto Parque Modernista em São Paulo, as quatro audio-instalações realizadas pelo Núcleo Oswaldiano de Rádio, posteriormente transmitidas pela Rádio Cultura FM. Foram elas: Explosão - Oswald em seu tempo; Invenção - Oswald e a modernidade; Antropofagia - Oswald e a devoração crítica; MIX 90 - Oswald e a contemporaneidade, minha criação, juntamente com Cíntia Sampaio de Gusmão e Eiko Akiyama.

Foi uma experiência única, recriamos e saboreamos biscoitos finos. Pela primeira vez estava explorando as possibilidades artísticas da linguagem radiofônica em sua totalidade. Infelizmente, ao contrário do que ocorre em rádios de outros países, esse gênero radiofônico não é incentivado e divulgado no Brasil.

Em dezembro de 90 concluí o curso de graduação. Com o diploma na mão, chegou a hora de procurar emprego. Sim, porque com a conclusão do curso concluí também o estágio.

\section{DE VOLTA À CULTURA AM}

Após alguns meses desempregado, voltei para a Rádio Cultura. Em 1991, deixei minha "erudição" de lado e fui contratado pela Rádio Cultura $\mathrm{AM}$, emissora que, na época, já dedicava sua programação à música brasileira, para trabalhar na Discoteca da Fundação Padre Anchieta, chefiada por Fausto Macedo, que, até seu falecimento recentemente, era considerado o mais antigo radialista em atividade. Após minha passagem pela Discoteca, trabalhei com Vilmar Bittencourt, diretor de programas da Rádio $\mathrm{AM}$, que havia sido um dos responsáveis pelo projeto de conclusão do meu curso de graduação. Com Vilmar, produzi programas para a série $O s$ dois lados do disco - ganhadora do Prêmio APCA 1991 de melhor musical $\mathrm{AM}$, Música, divina música e As músicas que fizeram sua cabeça. Agradeço a Vilmar por ter confiado no meu trabalho, permitindo que eu editasse e criasse programas dentro da série As músicas que fizeram sua cabeça, o que me possibilitou significativo crescimento profissional. 


\section{UM NOVO DEGRAU}

Em 1993 assumi total responsabilidade pelos programas Língua brasileira (hoje Nossa Língua Portuguesa, transmitido inicialmente pela Rádio Cultura AM e, posteriormente, adaptado para a TV) e Movimento - ginástica pelo rádio.

O programa Movimento - ginástica pelo rádio, uma parceria da Secretaria de Estado de Esportes e Turismo com a Rádio Cultura AM de São Paulo, era apresentado pela professora Maria Zeni Bannitz. Ele possuía significativa audiência, constatada pelo número de ouvintes inscritos, que recebiam gratuitamente a apostila para o acompanhamento das aulas. O Movimento era transmitido duas vezes por semana, às 7 horas da manhã.

O Nossa Língua Portuguesa, criado inicialmente como Língua brasileira, apresentado pelo professor Pasquale Cipro Neto, está no ar desde 31 de março de 1992. É um programa dinâmico e inovador, que conversa sobre nosso idioma, utilizando música brasileira, jornais e as mais variadas formas de expressão. É apresentado pela Rádio Cultura AM, em módulos diários, durante a programação, e semanalmente são produzidos dois programas inéditos de 30 minutos, que vão ao ar às quartas e sextas-feiras às 20 horas, com reapresentação aos sábados, às 7 horas da manhã.

Em 1994 passei a produzir também o programa Letra e música, idealizado pelo professor Pasquale Cipro Neto, no ar todas as terças-feiras às 18 horas. Seu propósito é analisar as letras de canções brasileiras, inserindo-as dentro de um contexto histórico e social. Temos informação de que existem grupos de ouvintes, no interior do Estado de São Paulo, que se reuniam para ouvir e discutir o conteúdo dos programas que foram levados ao ar. É a Rádio Cultura AM cumprindo um de seus papéis: levar aos ouvintes informações que despertem sua visão crítica.

É também de 1994 Trilha Brasil, série de programas que idealizei, roteirizei e dirigi. A série destacava as trilhas sonoras de filmes brasileiros, usando depoimentos de atores, diretores e compositores.

No ano de 1997, como parte das comemorações do Dia Internacional da Criança no Rádio e na TV, promovido pelo Unicef, em um esforço conjunto, a Rádio Cultura AM levou ao ar um dia inteiro de programação voltada à criança. Foram criados programas que, além de falar sobre a criança, permitiam que ela expressasse seu ponto de vista sobre o mundo.

Em 1999 idealizei a série Dramaturgia eletrônica - uma reflexão sobre a telenovela brasileira. Essa série, que foi produzida junta-

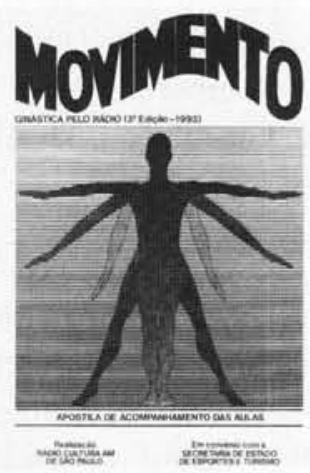

Apostila do curso de Ginástica pelo Rádio, Rádio Cultura/SP, 1993. 
mente com Teresinha Campos, surgiu tímida e foi ampliada quando entramos em contato com o Núcleo de Pesquisa de Telenovela da ECA/ USP, que teve grande importância para a realização desse projeto. Fizemos cerca de onze horas de entrevistas, gastamos alguns dias pesquisando livros, jornais e materiais do arquivo da Fundação Padre Anchieta. Após seis meses de trabalho, foram realizados quatro programas que tratavam de diversos aspectos da telenovela brasileira.

$\mathrm{O}$ primeiro programa traçava um pequeno histórico sobre o advento do rádio no Brasil, o surgimento da TV e o declínio das radionovelas, preparando o ouvinte para os temas que viriam nos programas seguintes. Elementos ligados à estrutura da telenovela e temas como preconceito racial, merchandising social e tantos outros assuntos foram abordados ao longo dos programas, que renderam boas críticas na imprensa, o que para nós é motivo de orgulho.

Apesar dos percalços, sinto-me privilegiado por fazer parte de uma equipe de diretores e produtores de programas que, ao longo desses anos, tem como objetivo oferecer aos ouvintes programas de alta qualidade.

Resta dizer que, devido à má localização e baixa potência dos transmissores da Rádio Cultura AM, sua sintonização é deficiente em algumas localidades, mas vale a pena a tentativa de sintonizá-la e assim conseguir desfrutar da nossa programação.

Resumo: João Antônio Batista conta sua trajetória de estagiário a produtor de programas para as Rádios Cultura FM e AM. Faz um breve histórico das duas emissoras, fala de seu prazer trabalhando como radialista e dos programas que pôde produzir e dirigir na rádio, tais como: $A s$ músicas que fizeram sua cabeça (1991); Nossa Língua Portuguesa (1992); Letra e música (1994); Trilha Brasil (1994) e Dramaturgia eletrônica - uma reflexão sobre a telenovela brasileira (1999). Destaca ainda as possibilidades de criação artística permitidas pela linguagem radiofônica.

Palavras-chave:Rádio Cultura, linguagem radiofônica, música brasileira, radialista, produção, erudito
Abstract: João Antônio Batista tells his trajectory, going all the way from his work as an intern to the producer of programs for Rádio Cultura, FM and AM. He draws a brief history of the two stations, talks about his pleasure at working in the radio and about the programs he produced and directed there, such as: As músicas que fizeram sua cabeça (The tunes that touched your mind) (1991); Nossa Língua Portuguesa (Our Portuguese Language) (1992); Letra e música (Lyrics and music) (1994); Trilha Brasil (Brazil Track) (1994) and Dramaturgia eletrônica - uma reflexão sobre a telenovela brasileira (Electronic Dramaturgy, a reflection on the Brazilian soap opera) (1999). He also emphasizes the artistic creation possibilities allowed for by the radio language.

Key words: Rádio Cultura, radio language, Brazilian music, broadcaster, production, erudite 